\title{
LA LEY DE BASES DEL ESTATUTO DEL REGIMEN LOCAL
}

$352(46)$

por

Juan Mahíllo Santos

SUMARIO: I. ANTECEDENTES.-II. ELABORACION Y APROBACION DE DICHA LEY.-III. PRINCIPALES PUNTOS DEBATIDOS E INNOVACIONES INTRODUCIDAS: 1. ENMIENDAS A LA TOTALIDAD. 2. ENtidades locales. 3. Población municipal. 4. El ayuntamiento. 5. El Alcalde. 6. Organización municipal. 7. Entidades municipales METROPOLITANAS. 8. ENTIDADES MUNICIPALES DE AMBITO COMARCAL $Y$ otros Regfmenes especiales. 9. Diputación Provincial. 10. Regfmenes ESPECIALES Y MANCOMUNIDADES PROVINCIALES. 11. HaCIENDAS locales. 12. Función pública. 13. Otras CUeStiones.-ANEXOS 1, 2 Y 3.

\section{ANTECEDENTES}

El día 17 de diciembre de 1971 el entonces Ministro de la Gobernación, GaRICANo GoÑI, presentó al Gobierno un Proyecto de Ley de Bases de Régimen local, dando así cumplimiento a lo ordenado por Decreto-ley 23/1969, de 16 de diciembre, que, al suspender el mandato contenido en la disposición final primera de la Ley $79 / 1968$, de 5 de diciembre, justifica tal suspensión en la necesidad de una nueva legislación básica del Régimen municipal y provincial cuyo proyecto, o, en su caso, proyectos parciales de reforma deberían haber sido enviados por el Gobierno a las Cortes con anterioridad al día 1 de enero de 1972.

El propósito de una reforma profunda del Régimen local data de más antiguo, ya que la Ley 48/1966, de 23 de julio, había man- 
dado al Gobierno que, dentro del plazo de dieciocho meses, enviara a las Cortes un Proyecto de Ley de Régimen local.

El Proyecto GaRICANo GoÑI, a pesar de la posibilidad que ofrecía el artículo $1 .^{\circ}$ del Decreto-ley 23/1969 de reformas parciales, optó por la solución de la reforma total. Dicho Proyecto constaba de 103 bases, 8 disposiciones finales y otras tantas transitorias.

El Proyecto del Gobierno fue publicado en el Boletín Oficial de las Cortes Españolas de 19 de enero de 1972, siendo enviado a la Comisión de Gobernación para su estudio. En la misma fecha se nombra la Ponencia encargada de informarlo y constituida por los señores Calderón Ostos, Ramos Fernández, Utrera Ravassa, De la Vallina Velarde y Viola Sauret. Posteriormente hubo cambios en la Ponencia, entrando a formar parte de la misma el señor HERRERo TEJEDOR.

Fue ímproba la labor de la Ponencia para estudiar y examinar más de 4.500 escritos de enmienda que habían sido presentados a dicho Proyecto. Estaban ultimados los trabajos del informe de dichas enmiendas cuando surgieron dificultades de naturaleza diversa y, posteriormente, como dice Ricardo DE LA CIERva, el trauma nacional inducido por el asesinato del Almirante-Presidente CARRERo Blanco. Posiblemente las escasas esperanzas de que el Proyecto GARICANO GoÑI llegara a convertirse en Ley, quedaron casi totalmente anuladas con el cambio de Gabinete que se produjo en junio de 1973 y, todavía más, con la desaparición, en diciembre de dicho año, del Presidente del Gobierno.

El nuevo Presidente del Gobierno, Arias Navarro, en su discurso programático de 12 de febrero de 1974 anuncia, entre otras materias objeto de reforma, la presentación de un nuevo Proyecto de Ley de Bases del Régimen local, cumpliendo dicho propósito cuando, a los pocos meses (concretamente a mediados de mayo, o sea, escasamente tres meses), se envía a las Cortes Españolas el Proyecto de Ley de Bases del Estatuto del Régimen local: la introducción del término Estatuto fue debida, en el decir de personas autorizadas, en homenaje al insigne municipalista Calvo Sotelo.

\section{ELABORACION Y APROBACION DE DICHA LEY}

Al Consejo de Ministros de mediados de mayo de 1974, el entonces Ministro de la Gobernación y Vicepresidente primero del Go- 
bierno, García Hernandez, presenta el Proyecto de Ley de Bases del Estatuto del Régimen local, conteniendo, además de un doctrinal y bien acabado preámbulo de exposición de motivos, 47 Bases, 5 disposiciones finales y otras tantas transitorias.

En el Boletín Oficial de las Cortes Españolas del día 31 de mayo de 1974 se publica dicho Proyecto para que, en el plazo de veinte días contados a partir del siguiente a la publicación, puedan presentarse las enmiendas que estimen pertinentes formular, a la totalidad o al articulado, los Procuradores. Se atribuye el estudio de dicho Proyecto a la Comisión de Gobernación y se designa la Ponencia para informar las enmiendas integrada por los señores GARcfa Romeu, Gómez Picazo, Herrero Tejedor, Lamo de Espinosa y De la Vallina Velarde.

Fue ampliado el plazo de presentación de enmiendas. Por otra parte, la Presidencia de las Cortes, con fecha 24 de julio de 1974, pidió un dictamen consultivo a la Comisión de Hacienda con referencia a las Bases relativas a las Haciendas locales. Al ser nombrado Ministro Secretario del Movimiento Herrero TeJedor, fue sustituido en la Ponencia por el señor Palomares Díaz.

Se presentaron 2.557 escritos de enmiendas, de los cuales seis estaban referidos a la totalidad del Proyecto. El número total de primeros firmantes asciende a 322 Procuradores (la inmensa mayoría de los escritos de enmienda están firmados por un solo enmendante). Hay que advertir, por una parte, que hay escritos de enmiendas conteniendo exclusivamente una referida a una Base determinada, e incluso a un solo apartado concreto dentro de la Base; y que, por el contrario, hay escritos referidos a una multiplicidad de Bases y apartados; por otra parte, un número bastante elevado de enmiendas fueron hechas por diversos Procuradores, o sea, coincidiendo éstos en los textos propuestos e, incluso, en las motivaciones en que se apoyan. De aquí que el número de escritos no sea suficientemente significativo y que, por el contrario, ofrezca una mayor información el número de enmiendas no repetitivas, entendiendo por tales las formuladas a cada uno de los apartados o párrafos de cada Base: tras una labor ímproba del Gabinete de Estudios del Servicio Nacional de Inspección y Asesoramiento de las Corporaciones Locales, de clasificación de las enmiendas por $\mathrm{Ba}$ ses y apartados, con especificación del número de Procuradores que 
las formulan, se presenta al final de esta Crónica un cuadro-resumen de enmiendas y enmendantes.

La Comisión de Hacienda, como resultado de las reuniones celebradas los días 5, 6, 7, 11 y 12 de febrero de 1975, emitió el dictamen consultivo que fue publicado en el Boletin Oficial de las Cortes Españolas del día 6 de marzo de 1975. Consta de dos partes: una primera, de carácter informativo, en la que, tras los antecedentes, examina las Bases relativas a las Haciendas locales exponiendo el criterio de la Ponencia y la decisión de la Comisión, y una segunda proponiendo la redacción a dichas Bases (19 a 36, con adición de algunas disposiciones finales y transitorias).

Por su parte, la Ponencia de la Comisión de Gobernación emite el informe preceptivo analizando y estudiando las enmiendas presentadas a la totalidad y a cada una de las Bases y, dentro de éstas, a los diversos apartados, terminando con un anexo conteniendo el texto propuesto por dicha Ponencia y que habría de servir de punto de partida para las deliberaciones y discusiones en el seno de la Comisión de Gobernación.

El día 14 de mayo de 1975, tras rechazarse por la Comisión de Gobernación las enmiendas a la totalidad del Proyecto, se inicia la discusión de la Base primera. Las vacaciones de las Cortes paralizan las discusiones, que continúan una vez finalizadas aquéllas, si bien reduciendo las mismas para la Comisión de Gobernación, ya que habría de reanudar los trabajos de deliberación sobre repetido Proyecto a partir del 9 de septiembre de 1975.

El 2 de octubre del mismo año queda ultimado el dictamen de la Comisión de Gobernación, apareciendo publicado en el Boletin Oficial de las Cortes Españolas del día 28 del mismo mes.

Inmediatamente se publican las enmiendas que, por haber obtenido número suficiente de votos favorables en el seno de la Comisión, podrían ser defendidas ante el Pleno de las Cortes. Dichas enmiendas versan sobre las siguientes cuestiones: totalidad (señor MARTÍN SANZ), reducción de edad para ser vecino (señor PEDROSA Latas), elección de Concejales (señores Lamo DE EsPinosa, Alcaina Caballero, Valdés larrañaga, Fugardo Sanz y Perpiñán ArellaNO), mandato de Concejal (señor Fugardo SANZ), elección de Alcalde (señores lamo De Espinosa, Bonilla San Rafael, Doreste Medina, Iglesia Somavilla, Gerona de la Figera, López González y JaRABo PayA), participación del Consejo Local del Movimiento en 
actos municipales de importancia (señor GÍAs Jové), regimenes provinciales especiales (señor MEILÁN GIL), impuesto sobre gastos suntuarios (señor ALONSo RoDRíGUEZ-NADALES), constitución de Cuerpos Nacionales (señor MOMBIEDRO DE LA TORRE) y primera renovación de las Corporaciones (señor AlCaINa Caballero).

El día 18 de noviembre de 1975, a las diez horas y diez minutos de la mañana, se abre la sesión del Pleno de las Cortes, en la que se iba a deliberar y someter a votación el dictamen emitido por la Comisión de Gobernación sobre el Proyecto de Ley de Bases del Estatuto del Régimen local, así como las enmiendas a dicho dictamen.

Se comienza con la defensa a la enmienda a la totalidad, defendida por el señor MARTín SANZ y que fue contestado por el Ponente señor De la Vallina Velarde. Sometida dicha enmienda a votación fue rechaza por 310 votos, obteniendo 31 votos a favor y habiendo 41 abstenciones.

Seguidamente intervienen, para defender sus enmiendas, los señores Pedrosa latas, lamo de Espinosa, Alcaina Caballero, Reus Cid, Valdés larrañaga, Bonilla San Rafael, De la Iglesia Somavilla, López González, Jarabo Payá, Gías Jové, Alonso Rodrí. guez-NADALES y MombIEDRo DE La TORRE. Responde en nombre de la Ponencia el Ponente señor Gómez Picazo. A continuación, el Vicepresidente primero del Gobierno y Ministro de la Gobernación, señor GARCÍA HERNÁNDEZ, expone las razones que abonan la conveniencia de la aprobación del dictamen.

Puestas a votación las anteriormente citadas enmiendas fueron rechazadas por el Pleno de las Cortes. (Se acompaña como anexo el resultado de las votaciones sobre las enmiendas defendidas ante el Pleno). El dictamen de la Comisión fue aprobado por el Pleno de las Cortes con 345 votos a favor, 33 en contra y 26 abstenciones.

El día 19 de noviembre de 1975 dicha Ley es sancionada por el Príncipe de España en funciones de Jefe del Estado interino, siendo publicada en el Boletín Oficial del Estado del día 21 de dicho mes. 


\section{PRINCIPALES PUNTOS DEBATIDOS E INNOVACIONES INTRODUCIDAS}

\section{ENMIENDAS A LA TOTALIDAD}

Justifican la oposición al Proyecto de Ley por las siguientes razones principales: ser anticonstitucional (los razonamientos y tesis son diversos según los enmendantes), se debe exigir un Proyecto de Ley articulada, el Proyecto ignora la realidad socio-politica del pais (los argumentos y tesis son diferentes), el Proyecto es incompleto, el Proyecto soslaya la participación de los órganos representativos de la Administración local, el Proyecto silencia los regimenes especiales de Vizcaya y Guipúzcoa, el Proyecto es inoportuno, etc.

Como se ha dicho anteriormente, las enmiendas a la totalidad fueron desechadas, unas en el seno de la propia Comisión de Gobernación y otras en el Pleno de las Cortes.

\section{ENTIDADES LOCALES}

Un punto objeto de enmienda fue el relativo a distinguir, por una parte, el Municipio y la Provincia como Entidades fundamentales frente a las restantes Entidades locales, o sea, diferenciar las Entidades locales fundamentales de las que no tienen este carácter de fundamentabilidad. Esta tesis prosperó.

Otra cuestión debatida es la matización relativa a que los Municipios son Entidades naturales y no, como se dice en el Proyecto, tienen la consideración de Entidades naturales. También prosperó esta tesis.

Con respecto a la Provincia, se modificó el concepto que figuraba en el Proyecto para ser sustituido por el que se contiene en el artículo 45, 2, de la Ley Orgánica del Estado.

En esta materia se planteó el delicado problema de la Región. Sin perjuicio de demorarse el debate del tema al momento de estudiarse el régimen provincial, la Comisión llegó a la solución de admitir la creación de entes regionales y comarcales de tipo asociativo y siempre para la realización de alguno de los fines atribuidos a las Entidades locales fundamentales (Municipio y Provincia) $o$ para los que les sean encomendados por la Administración pública. 


\section{Población MUNICIPAL}

Las cuestiones debatidas son principalmente las siguientes:

a) En cuanto a la edad para adquirir la condición de vecino. Tanto el Proyecto del Gobierno como la tesis que prosperó parten de que para tener la condición administrativa de vecino es requisito ser mayor de edad o emancipado, basándose, por una parte, en que las Entidades locales son Corporaciones de tipo económicoadministrativo y, por otra, que no deben participar en las funciones de dichos entes quienes no tengan plena capacidad jurídica de obrar. En contra de ello, un grupo importante de enmendantes sostiene que debe ser vecino el mayor de dieciocho años, alegando una serie de razones para ello; como se ha dicho anteriormente, esta última postura fue defendida ante el Pleno de las Cortes, siendo rechazada.

b) Se mantiene la tesis tradicional de la previa distinción entre residente y transeúnte.

c) Hay que destacar el hecho de que frente a la tesis tradicional de considerar al padrón municipal de habitantes como un instrumento público fehaciente, y tal como se decía en el Proyecto del Gobierno, el texto de la Ley lo configura como un documento público.

\section{El Ayuntamiento}

La Base 4 del Proyecto del Gobierno fue, sin género de dudas, la más discutida en el seno de la Comisión de Gobernación, dando lugar al mayor número de enmiendas con votos suficientes para ser defendidas ante el Pleno de las Cortes.

Las cuestiones planteadas y objeto de debate fueron principalmente las siguientes:

a) Grupos representados. Mientras unos enmendantes mantienen los grupos del Proyecto (familiar, sindical y corporativo), aunque variando la posición de los electores dentro del mismo, así como alterando la proporción representativa de cada grupo, otros sostienen una composición bipartita (grupo familiar y sindical) y 
un tercer bloque de enmiendas se inclina por como composición cuatripartita (grupos familiar, sindical, corporativo y municipal).

b) Electores. Las enmiendas presentadas sostienen criterios muy distintos, enlazando esta cuestión con la referente a los grupos que han de componer el Ayuntamiento.

c) Elegibles. Derechos de presentación. Proclamación de candidatos. La mayoría de las enmiendas están conformes con la doble condición de vecinos y la pertenencia al grupo por el que haya de presentarse el candidato. Hay posiciones que propugnan por la participación de los órganos del Movimiento en el proceso de constitución del Ayuntamiento.

Estas tres cuestiones aparecen sistematizadas en el anexo número 3, tal como se deduce del informe de la Ponencia.

Como innovaciones de la Ley aprobada con referencia al Proyecto del Gobierno hay que destacar las siguientes:

- Supresión de la referencia a los órganos administrativos.

- Alusión concreta al derecho de presentación de candidatos por cada uno de los cauces representativos.

- Concretar que la elección será por sufragio articulado emitido en forma directa, igual y secreta.

- Cuando no haya representación de grupos corporativos, por carecer el Municipio de un mínimo de entidades de este cauce, las vacantes acrecentarán, por partes iguales, a las otras dos representaciones.

- Admitir las elecciones parciales en determinados supuestos.

- Recoger el principio de que los elegidos no estarán ligados por mandato imperativo alguno.

- Declarar obligatorio y gratuito el cargo de Concejal, sin perjuicio de las indemnizaciones que procedan.

- Señalar las causas de incapacidad, los motivos de incompatibilidad y las causas del cese o expiración del mandato, así como las facultades de la autoridad gubernativa para la suspensión de un Concejal en el ejercicio del cargo. (El Proyecto del Gobierno remitía estas cuestiones al desarrollo de la Ley de Bases).

\section{Alcalde}

Este fue otro de los temas sumamente polémicos. El gran número de enmiendas presentadas pueden agruparse con referencia a 
los principales temas debatidos, los cuales fueron sistmatizados por la Ponencia en su informe:

a) Electores. Existen los siguientes grupos de enmiendas:

- Que el Alcalde sea elegido por todos los vecinos.

- Que el Alcalde sea elegido por una Comisión mixta y paritaria formada por Concejales y Consejeros locales del Movimiento.

- Que sea designado por el Gobierno o el Gobernador civil dentro de una terna formada por acuerdo del Ayuntamiento o por una Comisión mixta paritaria de éste y el Consejo Local del Movimiento.

- Fórmulas singulares, como, por ejemplo, elección por compromisarios designados por los vecinos, elección por Comisiones de Concejales y representantes de las diversas asociaciones, etc.

b) Condiciones de los elegibles, procedimiento de elección y cómputo de quorum. Las enmiendas presentadas ofrecen matices muy diversos: proclamación de los candidato por el Consejo Local del Movimiento, terna formada por dicho Consejo y el Ayuntamiento, terna formada exclusivamente por el Ayuntamiento, etc.

La Ponencia aclaró en la necesidad de distinguir entre el derecho de presentación y el acto formal de la proclamación de los candidatos.

Como innovaciones más sobresalientes de la Ley 41/1975 frente al Proyecto del Gobierno hay que destacar las siguientes:

- Determinar concretamente el derecho de presentación (por el propio candidato por haber sido o ser Alcalde o Concejal, propuesta por un número determinado de vecinos, propuesta por cuatro Consejeros locales del Movimiento y propuesta por las asociaciones políticas).

- Establecimiento del mismo quorum, con independencia de que el elegido sea o no Concejal.

- Aplicación de las causas de incapacidad, incompatibilidad, cese y renuncia establecidas para los Concejales.

- Supresión de la posible destitución por acuerdo corporativo.

- Regulación de la figura del Teniente de Alcalde y de la posibilidad de que el Alcalde delegue atribuciones en los Concejales.

- Admite la posibilidad de que los Alcaldes perciban asignacio. nes de acuerdo con lo que legalmente se establece. 


\section{ORganización MUNICIPAL}

En cuanto a las Bases 6 y 7 del Proyecto, hay que destacar la sustitución de la Comisión Administrativa por la Comisión Permanente, integrada exclusivamente por miembros electivos, sin perjuicio de que forme parte de la misma, así como del Pleno, el Secretario, con voz pero sin voto. Se mantiene la posibilidad de nombrar Directores de los Servicios especializados, los cuales, juntamente con los Jefes de los Servicios generales, podrán asistir a las sesiones de los órganos corporativos.

\section{ENTIDADES MUNicipales METROPOLITANAS}

Como innovaciones introducidas en la Ley con referencia el Proyecto del Gobierno, hay que señalar las siguientes:

- El Presidente de la Entidad será elegido por el propio Consejo entre sus miembros y no por Decreto entre los Alcaldes, como decía el Proyecto.

- Se exige para la constitución de la Entidad el acuerdo favorable del Ayuntamiento que represente el núcleo de mayor censo de población, y en todo caso el del Ayuntamiento de la capital de la Provincia, cuando ésta resulte afectada.

- Se exige el dictamen del Consejo de Estado cuando haya oposición por parte de alguno de los Municipios afectados.

\section{ENTIDADES MuNicipales de Ámbito comarcal y otros REGfMENES ESPECIALES}

La Ponencia en su informe añadió una nueva Base, en la que se regulan los principios de creación y funcionamiento de estas Entidades; con escasas diferencias, el texto del informe de la Ponencia ha pasado a constituir la Base 10 de la Ley.

Por lo que respecta al régimen de los pequeños Municipios, en virtud de las enmiendas y del informe de la Ponencia, se han hecho modificaciones de distinta naturaleza en la Base 10 del Proyecto y 11 de la Ley, siendo de destacar la supresión de la Comisión Administrativa. 
Con referencia a los regímenes municipales especiales y constitución de Mancomunidades y Agrupaciones municipales, hay que advertir que la Ley aprobada matiza los procedimientos de creación, cosa que no hacía el Proyecto del Gobierno.

\section{DIPUTACIÓN PROVINCIAL}

Lo que se ha dicho con referencia al Municipio, y especialmente en lo relativo a elección de Concejales y Alcalde, es de aplicación a la de los cargos análogos en la Diputación, así como también lo concerniente a la desaparición de la Comisión Administrativa. Como innovaciones más importantes hay que destacar las siguientes:

- Cambio sustancial en la elección de Diputados, estableciéndose los grupos familiar, sindical, corporativo y municipal.

- Son electores los Concejales de los Municipios de la Provincia que lo sean por el respectivo cauce representativo.

- Se establece la Comisión de Gobierno en sustitución de la Comisión o Junta Administrativa, determinándose su composición y competencia.

- Se concretan más que en el Proyecto las materias que entran dentro de la capacidad y competencia provinciales.

- Se regula la obligación de las Diputaciones de prestar, por regla general, el Servicio de Extinción de Incendios, salvo las excepciones que se señalan en la propia Ley.

\section{REGfMENES ESPECIALES Y MANCOMUNIDADES PROVINCIALES}

La Comisión ha añadido la Base 19, recogiendo preceptos que estaban dispersos en varios puntos del Proyecto. El contenido de dicha Base se refiere a los siguientes extremos:

a) Régimen de Carta provincial, si bien respetando los principios esenciales de la Ley y con ciertos condicionantes.

b) Respetar los regimenes de las Provincias de Alava y Navarra, del Archipiélago canario y de las ciudades de Ceuta y Melilla.

c) Mandato para establecer un régimen administrativo especial en los Archipiélagos canario y balear.

d) Concebir los Municipios de Ceuta y Melilla bajo una fórmula de Municipio-Provincia, al decir que los Ayuntamientos de dichas 
ciudades percibirán, además, los ingresos que corresponden a las Diputaciones.

En cuanto a las Mancomunidades provinciales, la Base 19 de la Ley ha introducido ciertas innovaciones, más o menos sustanciales, con referencia a la Base 18 del Proyecto. Las principales modificaciones son las siguientes:

- Se introduce como motivación de las Asociaciones entre Provincias el promover y colaborar en la acción de desarrollo regional $e$ interprovincial, si bien manteniéndose el principio del Proyecto de que no pueden constituirse Mancomunidades provinciales para la totalidad de las competencias asignadas a las respectivas Diputaciones.

- Se concreta el procedimiento de constitución de Mancomunidades provinciales.

- Se admite que dichas Mancomunidades pueden ser disueltas por el Gobierno por razones de orden público o seguridad nacional.

\section{Haciendas LOCALES}

En materia de Haciendas locales (Bases 21 a 37 de la Ley), las principales innovaciones introducidas con referencia al Proyecto del Gobierno son las siguientes:

a) Desaparición del proyectado Impuesto sobre Residencia (posiblemente la honda oposición a este proyectado impuesto pudiera estar motivada por una interpretación no suficientemente adecuada de la naturaleza del mismo, de su finalidad y de los amplios sectores de contribuyentes-consumidores de servicios generales que se incorporarían a la tributación municipal): se presentaron 38 enmiendas a esta Base.

b) Se establece el principio de que la obligación de contribuir es siempre general y que toda exención o bonificación de la imposición local autónoma exigirá disposición con rango de ley, sin perjuicio de respetar los derechos adquiridos derivados de la legislación anterior en cuanto a exenciones y bonificaciones.

c) En materia de Tasas, las innovaciones son las siguientes:

- No considerar aprovechamiento especial cuando se trate de concesiones de servicios de transportes colectivos urbanos de viajeros otorgadas por el Municipio de la imposición. 
- Poner como límite de la tasa el coste del servicio.

- Aclarar que las tasas no tendrán la consideración de rentas ni de precios.

d) En cuanto al Impuesto de Solares, las modificaciones principales son las siguientes:

Gravar también los suelos urbanos y urbanizables programados, aun cuando no tengan la condición de solar.

- Suspensión de la aplicación del impuesto cuando estén suspendidas las licencias y durante el tiempo de ejecución de las obras.

- No gravar los solares edificados, con lo cual los Ayuntamientos perderán el rendimiento del antiguo arbitrio especial de solares edificados y sin edificar.

- En compensación se elevan los tipos impositivos con los límites mínimo y máximos de 1,5 y 6 por 100 para los solares y el 0,50 y el 6 por 100 , respectivamente, para los terrenos urbanos o urbanizables programados que no sean solares.

- La recaudación del impuesto por los terrenos urbanos y urbanizables programados, que no sean solares, tendrá carácter de finalista.

Algunas de las modificaciones introducidas son consecuencia de la Ley de Reforma de la del Suelo.

e) En cuanto al Impuesto de Radicación hay que decir, en primer lugar, que hubo un número considerable de enmiendas que pedían que no se gravaran los locales para el ejercicio de actividades profesionales. Estas enmiendas fueron rechazadas, si bien se aclaró el texto del Proyecto en el sentido de que cuando un local se destine conjuntamente a la actividad profesional y vivienda, el impuesto sólo afectará a la parte destinada a la actividad profesional.

Se amplía el impuesto a los Municipios capitales de Provincia, aun cuando tengan población no superior a 100.000 habitantes.

Otras innovaciones introducidas en el Proyecto son las siguientes:

- Se reduce al 40 por 100 , en lugar del 50 por 100 , el incremento de la cuota en una categoría de calles con referencia a la cuota inmediata inferior, si bien manteniendo las normas especiales en los Municipios de Madrid y Barcelona con referencia a este extremo. 
- Se añade que el Texto articulado determinará las tasas que quedan absorbidas en este impuesto.

- También se añade que, independientemente de que el impuesto es anual, las cuotas se devengarán por mitad en cada semestre.

- Autoriza a que el Texto articulado regule las exenciones y bonificaciones por razón de la actividad del sujeto pasivo o por otras causas de interés social o público, sin perjuicio de que reconocerá la exención a los centros de enseñanza reconocidos y autorizados por el Ministerio de Educación y Ciencia y a los hospitales, clínicas y demás establecimientos sanitarios en la parte en que estén destinados a fines de asistencia y seguridad social.

f) Impuesto de Circulación. Las principales innovaciones son las siguientes:

- En cuanto a las tarifas de los turismos, se establecen nuevos grupos, reduciendo las cuotas de los vehículos pequeños y aumentando la de los grandes. Se suprime el gravamen para los carros y otros vehículos de tracción animal y para las bicicletas. En cuanto a las motocicletas, se discriminan las tarifas en atención a la cilindrada.

- Ordena que el Texto articulado regule las condiciones que sirvan para determinar las exenciones y bonificaciones por razones de interés público o social.

- Se amplía la exención a los autobuses urbanos adscritos a transporte público en régimen de concesión municipal.

g) Impuesto sobre incremento de valor de los terrenos. Las principales innovaciones introducidas por la Ley con referencia al Proyecto son las siguientes:

- En cuanto al ámbito de aplicación, se sustituye el criterio de sujetar a los terrenos afectos a explotaciones agrícolas, ganaderas, forestales o mineras cuando su valor sea el triple de la capitalización al 4 por 100 de la base imponible, por el de sujetar a dichos terrenos cuando estén calificados como urbanos o urbanizables programados.

- No habrá lugar o devengo en los casos de concentración o agrupación de empresas.

- En cuanto a la tasa de equivalencia, se mantiene el periodo decenal de la vigente Ley, en lugar del período quincenal que figuraba en el Proyecto. 
- También con referencia a dicha tasa, el tipo se reduce al 5 por 100, en lugar del tipo normal que figuraba en el Proyecto, si bien se aclara que esta tasa tendrá el carácter de cuota a cuenta de la que resulte en la liquidación en caso de transmisión.

- El límite de la cuota normal, que el Proyecto fijaba en el 50 por 100 , se reduce al 40 por 100 .

Hay otras modificaciones que tal vez puedan calificarse de naturaleza secundaria, aun cuando puedan tener repercusión económica para los Municipios.

h) Por lo que respecta al Impuesto sobre Gastos suntuarios, las modificaciones de la Ley con referencia al Proyecto son las siguientes:

- Suprimir el gravamen de las estancias en hoteles y establecimientos similares de tres estrellas, así como las consumiciones en dichos establecimientos, restaurantes y similares de tres tenedores.

- Suprimir el gravamen a los servicios funerarios (antiguo arbitrio sobre pompas fúnebres).

- Excluir del impuesto de entradas y consumiciones a las salas de fiestas y discotecas de juventud.

- Establecer el mínimo exento de 10.000 pesetas en cuanto a las cuotas de entrada de socios en sociedades o círculos deportivos o de recreo.

- Elevar a siete millones de pesetas el valor catastral mínimo para la sujeción de gravamen a las viviendas suntuarias.

- Suprimir el gravamen a las entradas en espectáculos públicos donde se crucen apuestas.

- Reducir el tipo imponible del impuesto que grava las consumiciones: el 20 por 100 que figuraba en el Proyecto queda reducido al 5 por 100, salvo en las consumiciones de aperitivos, cafés, licores, etc., que están gravadas con el 10 por 100.

- Elevación del tipo en las apuestas, ya que se pasa del 5 al 15 por 100.

i) Recargos municipales sobre Impuestos estatales. Se rebaja la cuota de la licencia fiscal del Impuesto industrial del 40 al 35 por 100 , y la de las primas de las Entidades mutuas de seguros del 40 al 30 por 100 .

También se suprime la posibilidad de que los recargos especiales y los determinados para fines específicos puedan ser convali- 
dados por el Ministerio de Hacienda, previo informe del de la Gobernación.

j) Presupuestos y Cuentas. Como novedades más importantes hay que citar, en primer lugar, que los presupuestos y ordenanzas fiscales no precisan aprobación de los órganos del Ministerio de Hacienda, los que sólo intervienen en caso de reclamación; sin embargo, hay un informe previo, a la aprobación corporativa, del Servicio de Asesoramiento e Inspección de las Corporaciones Locales.

Por lo que respecta a la aprobación definitiva de las cuentas y a los expedientes de alcance y reintegro, la competencia es de los órganos del Ministerio de la Gobernación, eliminándose la competencia del Tribunal de Cuentas del Reino que figuraba en el Proyecto, aun cuando los órganos del Ministerio de la Gobernación intervinieran, pero por delegación de dicho Tribunal.

\section{FUNCIÓN PÚBLICA}

Como novedad interesante hay que destacar el hecho de que se admite la posibilidad de creación de nuevos Cuerpos Nacionales.

Con respecto a la advertencia de ilegalidad, se ha eliminado la obligación de hacerla a los Presidentes de las Corporaciones.

\section{Otras CUestiones}

Se ha suprimido la disposición final tercera, que autorizaba al Gobierno para revisar las bases, cuotas y tipos señalados en pesetas, a fin de ajustarlos a las variaciones del índice general del coste de la vida. Esta supresión obligará, en cualquier caso, a nuevos proyectos de leyes cada vez que hayan de modificarse las cuotas o tipos.

También hay modificaciones en cuanto a la renovación de las Corporaciones locales y de los Presidentes de las mismas, sin perjuicio de que posteriormente se presentó un Proyecto de Ley modificando la disposición transitoria primera en parte. Dicha modificación ha sido aprobada en el Pleno de las Cortes del día 9 de marzo de 1976. 


\section{ANEXO NUMERO 1}

\section{BASES AFECTADAS}

1. Administración local

2. Población municipal $\ldots$

3. Términos municipales $\ldots \ldots \ldots \ldots \ldots \ldots$

4. Ayuntamiento $\ldots \ldots \ldots \ldots \ldots \ldots \ldots$

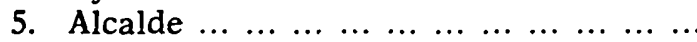

6. Servicios municipales y Comisión Admi-

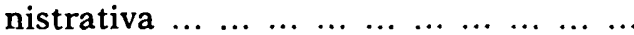

7. Atribuciones de los órganos municipales ... ... ... ...........................

8. Capacidad y competencia municipal ...

9. Entidades municipales metropolitanas.

10. Régimen Municipios de menos de 5.000 habitantes ...........................

11. Regímenes municipales especiales ... ...

12. Mancomunidades y Agrupaciones ......

13. Diputación provincial ... ... ............

14. Presidente de la Diputación ... ... ... ...

15. Servicios provinciales y Comisión Admi-

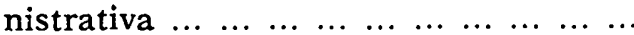

16. Competencia de los órganos provinciales ... .................................

17. Capacidad de la Entidad provincial ...

18. Mancomunidades provinciales ... ... ...

19 a 36. Haciendas locales ... ... ... ........

19. Ingresos locales $\ldots \ldots \ldots \ldots \ldots \ldots$

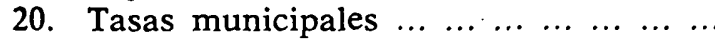

21. Contribuciones especiales de los Municipios $\ldots \ldots \ldots \ldots \ldots \ldots \ldots \ldots$

22. Impuesto municipal sobre Residencia ...

23. Impuesto municipal sobre Solares ... ...

24. Impuesto de Radicación ... ... ... ......

25. Impuesto rnunicipal sobre Circulación.

26. Impuesto sobre incremento de valor de los terrenos .........................

27. Impuesto municipal sobre Gastos sun-

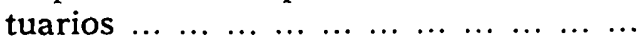

28. Impuesto municipal sobre Publicidad ...

28 bis. Nuevos impuestos ... ... ...........

29. Recargos municipales sobre impuestos del Estado ... ... . . . . . . . . . . . . . . . . . . . .

30. Participación en impuestos del Estado.
Número

Núm. de de enmenenmiendas dantes

251

94

58

112

134

683

425

83

177

51

113

218

129

100

68

25

49

274

229

108

39

90

34

110

48 
BASES AFECTADAS

31. Tasas y contribuciones provinciales ...

32. Recargos y participaciones provinciales en impuestos del Estado ..............

32 bis. Nueva $\ldots \ldots \ldots \ldots \ldots$

33. Crédito local $\ldots \ldots \ldots \ldots \ldots \ldots$

34. Beneficios tributarios $\ldots \ldots \ldots \ldots \ldots$

35. Presupuestos $\ldots \ldots \ldots \ldots \ldots \ldots$

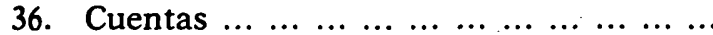

37. Potestades y privilegios de las Entidades locales ... ... ... ... ... ..............

38. Organización administrativa. Consor-

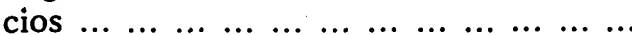

39. Función pública local $\ldots \ldots \ldots \ldots \ldots \ldots$

40. Procedimiento administrativo $\ldots . . . . . .$.

41. Organos de la Administración del Estado competentes en Administración lo cal $\ldots \ldots \ldots \ldots \ldots \ldots \ldots$

42. Funciones de la Administración del Estado sobre las Entidades locales ... ... ...

43. Responsabilidad $\ldots \ldots \ldots \ldots \ldots \ldots$

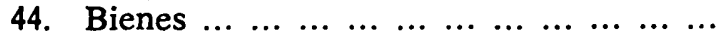

45. Contratación administrativa ... ........

46. Cooperación del Estado ................

47. Colaboración de las Entidades locales con el Estado ... .......................

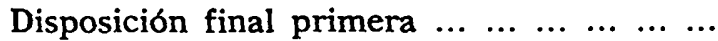

Disposición final segunda $\ldots \ldots \ldots \ldots \ldots$

Disposición final tercera $\ldots \ldots \ldots \ldots \ldots \ldots \ldots$

Disposición final cuarta $\ldots . \ldots \ldots \ldots \ldots \ldots$

Disposición final quinta ... ... . . . . ... .....

Disposición transitoria primera $\ldots \ldots \ldots \ldots$

Disposición transitoria segunda $\ldots \ldots \ldots \ldots$

Disposición transitoria tercera ..............

Disposición transitoria cuarta ... ... .........

Disposición transitoria quinta $\ldots \ldots \ldots \ldots \ldots$

Disposiciones nuevas $\ldots \ldots \ldots \ldots \ldots$

TOTAL
Núm. de enmiendas

13

15

53

1

9

17

31

6

24

13

46

26

17

49

\section{0}

14

26

10

27 Número
de enmen-
dantes

74

1

13

42

46

6

40

34

57

52

59

15

54

10

33

$8 \quad 8$

$18 \quad 32$

$33 \quad 44$

$7 \quad 28$

$5 \quad 8$

$9 \quad 30$

$34 \quad \cdot 49$

$7 \quad 14$

45

$7 \quad 12$

11

9

10 


\section{ANEXO NUMERO 2}

RESULTADO DE LA VOTACION DE LAS ENMIENDAS SOMETIDAS AL PLENO DE LAS CORTES ESPAÑOLAS

\begin{tabular}{|c|c|c|c|c|}
\hline \multirow{2}{*}{ Enmendantes } & \multirow{2}{*}{ Bases } & \multicolumn{3}{|c|}{$\mathrm{VOTOS}$} \\
\hline & & A favor & Abstención & Contra \\
\hline 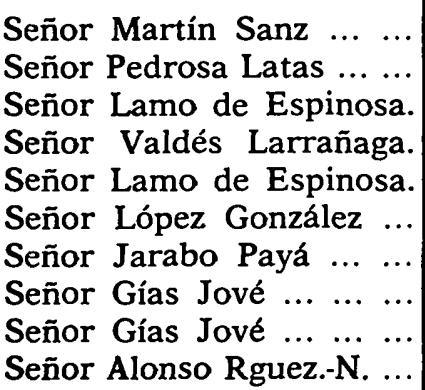 & $\begin{array}{l}\text { Totalidad } \\
2,2,1 \\
4,2 \\
4,2 \\
5,1 \\
5,1 \\
5,1 \\
7,1 \\
17,1 \text { bis } \\
28,4 \text {, a) }\end{array}$ & $\begin{array}{r}31 \\
142 \\
134 \\
80 \\
101 \\
92 \\
60 \\
61 \\
64 \\
42\end{array}$ & $\begin{array}{r}41 \\
6 \\
14 \\
17 \\
7 \\
7 \\
22 \\
11 \\
13 \\
25\end{array}$ & $\begin{array}{l}310 \\
264 \\
266 \\
302 \\
299 \\
300 \\
299 \\
319 \\
313 \\
336\end{array}$ \\
\hline . & & \multicolumn{3}{|c|}{ OBSERVACIONES } \\
\hline 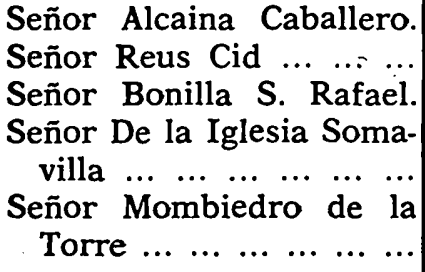 & $\begin{array}{l}4,2 \\
4,2, \mathrm{~b}) \\
5,1 \\
5,1 \\
\text { Final } 5 . \mathrm{a}\end{array}$ & \multicolumn{3}{|c|}{$\begin{array}{l}\text { Renunciaron al derecho a vota- } \\
\text { ción por el Pleno. }\end{array}$} \\
\hline
\end{tabular}

\section{ANEXO NUMERO 3}

ESQUEMA DE LAS POSICIONES DE LAS ENMIENDAS CON REFERENCIA A LAS ELECCIONES DE CONCEJALES

(Según resulta del informe de la Ponencia)

\begin{tabular}{|l|l|}
\hline \multicolumn{1}{|c|}{ Grupos } & \multicolumn{1}{c|}{ Posiciones sobre los electores } \\
\hline & A) $\begin{array}{l}\text { Unicamente los cabezas de familia o éstos y las } \\
\text { mujeres casadas. }\end{array}$ \\
$\begin{array}{l}\text { Representación } \\
\text { familiar. }\end{array}$ & $\begin{array}{l}\text { Todos los vecinos: algunos extienden el voto a } \\
\text { los mayores de dieciocho años. }\end{array}$ \\
& $\begin{array}{l}\text { No se pronuncian categóricamente, remitiéndose } \\
\text { a las disposiciones que se dicten al efecto en el } \\
\text { desarrollo de la Ley de Bases, por el Ministerio } \\
\text { de la Gobernación, por la Ley Electoral, etc. }\end{array}$ \\
\hline
\end{tabular}


REVISTA DE ESTUDIOS DE LA VIDA LOCAL

\begin{tabular}{|c|c|}
\hline Grupos & Posiciones sobre los electores \\
\hline $\begin{array}{l}\text { Representación } \\
\text { sindical. }\end{array}$ & $\begin{array}{l}\text { A) Todos los vecinos, todos los mayores de die- } \\
\text { ciocho años o cabezas de familia y mujeres ca- } \\
\text { sadas. } \\
\text { B) No se pronuncian al respecto: se remiten a las } \\
\text { disposiciones que se dicten sobre el particular. } \\
\text { C) Vecinos pertenecientes al tercio, pero sin concre- } \\
\text { tar más al respecto. } \\
\text { D) Remisión a la legislación específica de la Orga- } \\
\text { nización Sindical. } \\
\text { E) Vecinos del Municipio que sean trabajadores, } \\
\text { técnicos y empresarios. } \\
\text { F) Elecciones de segundo grado dentro de la Orga- } \\
\text { nización Sindical (representantes, compromisa- } \\
\text { rios, enlaces, cargos directivos, etc.). } \\
\text { G) Sindicados: elección directa o de segundo grado, } \\
\text { según el número de censados en cada término } \\
\text { municipal. }\end{array}$ \\
\hline $\begin{array}{l}\text { Representación } \\
\text { corporativa. }\end{array}$ & $\begin{array}{l}\text { A) Directa: de los miembros de las Asociaciones, } \\
\text { Entidades y Corporaciones. } \\
\text { B) Indirecta: mediante compromisarios de dichas } \\
\text { Asociaciones, Entidades o Corporaciones. } \\
\text { C) Vecinos integrados en el grupo, sin especificar } \\
\text { más. } \\
\text { D) Aisladas: Consejeros locales del Movimiento, } \\
\text { compromisarios de las Asociaciones del Movi- } \\
\text { miento, coparticipación de Consejeros y Conce- } \\
\text { jales, etc. } \\
\text { E) A lo que se disponga en el desarrollo de esta Ley } \\
\text { o en la Ley Electoral o en las normas que dicte } \\
\text { la Secretaría General del Movimiento. }\end{array}$ \\
\hline $\begin{array}{l}\text { Representación } \\
\text { vecinal. }\end{array}$ & $\begin{array}{l}\text { A) Todos los vecinos. } \\
\text { B) Los residentes mayores de dieciocho años. } \\
\text { C) Cabezas de familia y mujeres casadas. }\end{array}$ \\
\hline
\end{tabular}

